\title{
A relação Custo/Volume/Lucro na Produção de Arroz: Um Comparativo entre o Cultivo Pré-germinado e o Plantio Direto
}

Doutorando em Contabilidade pela Universidade Federal de Santa Catarina - UFSC Professor no Centro Universitário Franciscano - UNIFRA R. dos Andradas, 1614. Centro. Santa Maria/RS. Brasil. CEP: 97.010-032 E-mail: cristianocontador@hotmail.com

Lucas Wancura Barbieri Graduação em Ciências Contábeis pelo Centro Universitário Franciscano - UNIFRA E-mail: Iwbarbieri@hotmail.com

\section{RESUMO}

O estudo tem por objetivo identificar o custo do arroz na safra 2013/2014, considerando a relação custo/volume/lucro a partir de um comparativo entre as técnicas de cultivo pré-germinado e plantio direto. Para tanto, utilizou-se de uma abordagem qualitativa, descritiva, aliada ao estudo de caso, onde os dados foram coletados mediante pesquisa documental e entrevistas semiestruturadas. Com base na Teoria dos Custos de Transação (TCT), os custos agrícolas da produção rural de arroz foram abordados. A área rural estudada utiliza 205 hectares arrendados para o plantio, sendo o cultivo prégerminado empregado em $87 \%$ da área, enquanto o plantio direto é utilizado no restante. As variáveis "custo, volume e lucro" foram analisadas para identificar os resultados por tipo de plantio, tendo sido adotado, para apuração dos custos, o método de Custeio Direto. Os resultados indicam que a produção no cultivo pré-germinado apresenta menor custo de produção, maior produtividade e maior lucro em relação aos volumes produzidos por hectare, comparando com os resultados do plantio direto. Espera-se que esses resultados contribuam com os empresários rurais, agricultores e profissionais de contabilidade no processo decisório quanto à apuração dos custos agrícolas.

Palavras-chave: Contabilidade de custos. Custos no agronegócio. Custo da Rizicultura.

\section{The Cost/Volume/Profit Ratio in Rice Production: A comparative between pre- germinated cultivation and direct plantation}

\section{ABSTRACT}

The study aims to identify the cost of rice in the crop 2013/2014, considering the relation cost/volume/profit, from a comparison between the techniques of pre-germinated cultivation and no-tillage. For that, a qualitative, descriptive approach was used, allied to the case study, where data were collected through documentary research and semi- 
A relação Custo/Volume/Lucro na Produção de Arroz: Um comparativo entre o cultivo prégerminado e o plantio direto

Cristiano Sausen Soares, Lucas Wancura Barbieri

structured interviews. Based on the Transaction Costs Theory (TCT), the agricultural costs of rural rice production were addressed. The studied rural area uses 205 hectares leased for planting, with the pre-germinated crop being used in $87 \%$ of the area, while no-tillage is used for the rest. The variables "cost, volume and profit" were analyzed to identify the results by type of planting, and the method of Direct Costing was adopted for costing. The results indicate that the production in the pre-germinated crop presents lower cost of production, higher productivity and greater profit, in relation to the volumes produced per hectare compared with the results of no-tillage. It is hoped that these results will contribute to rural entrepreneurs, farmers and accounting professionals in the decision-making process regarding the determination of agricultural costs.

Keywords: Cost accounting. Costs in agribusiness. Cost of Curling.

\section{INTRODUÇÃo}

O arroz está entre os cereais mais cultivados e consumidos no mundo. Segundo a Companhia Nacional de Abastecimento [CONAB] (2015), o Brasil vem obtendo bons resultados na produção de arroz, sendo ressaltado o seu desempenho na safra 2013/2014, quando foram colhidas cerca de 12,8 milhões de toneladas do grão. O Rio Grande do Sul (RS) é o estado brasileiro com a maior produção de arroz no país, sendo largamente utilizado o método de cultivo irrigado. A região central do estado gaúcho destaca-se na produção do grão, especialmente a cidade de Cacequi, onde foram produzidas mais de 105 mil toneladas na safra 2013/2014.

Dentre os principais métodos de plantio de arroz utilizados no Brasil, cita-se o cultivo pré-germinado e o plantio direto, cabendo ao produtor definir o sistema de cultivo adequado, considerando-se as condições de produção, solo e clima. Após a definição das técnicas de plantio, a preocupação do produtor transfere-se para as questões relacionadas à gestão da produção, visando melhor qualidade e maior lucratividade, sendo inseridos, nessa análise, os fatores relativos à quantidade produzida, o lucro desejado e o custo da produção.

A apuração dos custos da produção rural pode auxiliar o produtor no processo decisório, fornecendo informações que viabilizem o planejamento e o controle das atividades, além de melhorar os resultados e evitar desperdícios (Hofer, Rauber, Diesel, 
A relação Custo/Volume/Lucro na Produção de Arroz: Um comparativo entre o cultivo prégerminado e o plantio direto

Cristiano Sausen Soares, Lucas Wancura Barbieri

\& Wagner, 2006). Contudo, os resultados da produção podem ser diferentes, dependendo do tipo de cultivo adotado. Assim, informações históricas acerca de safras anteriores podem auxiliar o produtor rural nessas decisões.

Neste contexto, apresenta-se a seguinte questão de investigação: Como se comportam as variáveis custo/volume/lucro na produção de arroz ao se comparar dois métodos de cultivo? Para responder a questão, o objetivo do estudo é analisar o comportamento do custo da produção de arroz na safra 2013/2014, comparando dois métodos de cultivo, considerando sua relação com o volume produzido e o resultado gerado.

Um dos fatores motivadores para a realização desta pesquisa foi o atual cenário favorável do agronegócio no país e a sua importância no contexto econômico, além de fortalecer a utilização da contabilidade de custos como instrumento de gestão, considerando-se que pequenos produtores tendem a utilizar pouco as informações geradas pela contabilidade de custos como ferramenta decisória (Borilli, Philippsen, Ribeiro, \& Hofer, 2008). Os resultados aqui evidenciados podem subsidiar o processo de tomada de decisão dos produtores rurais, auxiliar no planejamento da safra e a tornar o produto mais competitivo no mercado, obtendo melhores resultados (Santos, 2007).

Pesquisas relacionadas à apuração do custo da produção de arroz são encontradas na literatura (Brondani, Madruga, Trindade, \& Venturini, 2006; Wander, 2006; Borges, Mainardi, \& Velasquez, 2013; Bassani \& Breda, 2012), porém sem considerar a relação custo/volume/lucro nas suas análises. Assim, justifica-se o estudo, tendo como aspecto contributivo a relação do custo da produção de arroz com o volume produzido e o resultado apurado no comparativo entre dois métodos de cultivos. Outro diferencial deste estudo reside no fato de que os dados foram coletados diretamente em uma única propriedade rural localizada na cidade de Cacequi/RS, produtora de arroz, onde são adotados ao mesmo tempo dois sistemas de cultivo, viabilizando a comparação. 
A relação Custo/Volume/Lucro na Produção de Arroz: Um comparativo entre o cultivo prégerminado e o plantio direto Cristiano Sausen Soares, Lucas Wancura Barbieri

Assim, o presente estudo apresenta-se em quatro seções, além desta Introdução. Na seção seguinte, são apresentados os aspectos teóricos; na sequência, os aspectos metodológicos, seguidos dos resultados. Por fim, são apresentadas as considerações finais e as referências utilizadas.

\section{REFERENCIAL TEÓRICO}

O cultivo do arroz destaca-se pela produção e extensão de área plantada, desempenhando papel estratégico, tanto no aspecto econômico quanto no social. No mundo, cerca de 150 milhões de hectares de arroz são cultivados, produzindo mais de 590 milhões de toneladas de grãos. Dessa produção, mais de $75 \%$ são oriundos do sistema de cultivo irrigado (Embrapa, 2005).

O Brasil se destaca como o maior produtor de arroz fora do continente asiático, sendo que o sistema de cultivo irrigado é tradicionalmente praticado na Região Sul do país, devido às questões de clima e solo, contribuindo, em média, com 54\% da produção nacional. Nesse contexto, dentre os estados brasileiros, o Rio Grande do Sul é o maior produtor de arroz do país (CONAB, 2015).

\subsection{Métodos de cultivo na rizicultura}

As formas de plantar arroz são agrupadas em dois grandes sistemas: semeadura direta e transplantio. A principal diferença entre esses sistemas é que, no plantio direto, as sementes secas são lançadas diretamente no solo ou pré-germinadas, a lanço ou em linhas, em solo seco ou inundado; já no sistema de transplantio, as plântulas são produzidas primeiramente em viveiros ou sementeiras, antes de serem levadas para 0 local de plantio definitivo (Embrapa, 2005).

O plantio direto é o sistema que utiliza menor mobilização do solo (Brondani et al., 2006). No caso do arroz irrigado, o preparo do solo tanto pode ser realizado no verão como no final do inverno ou início da primavera, obedecendo-se uma 
A relação Custo/Volume/Lucro na Produção de Arroz: Um comparativo entre o cultivo prégerminado e o plantio direto Cristiano Sausen Soares, Lucas Wancura Barbieri

antecedência mínima que permita a formação de uma cobertura vegetal. O controle de plantas daninhas, antes e depois do plantio direto, é geralmente feito com herbicidas.

A adoção dos sistemas de plantio direto (PD) na cultura do arroz irrigado na Região Subtropical do Brasil teve como objetivo inicial o controle do arroz-vermelho, considerado uma das principais pragas na plantação desse grão, de modo que nem todos os princípios básicos dos sistemas são praticados em sua plenitude (Embrapa, 2005). O uso do plantio direto, além de minimizar o problema do arroz-vermelho, proporciona outros benefícios à rizicultura, cujos resultados têm contribuído para que a área cultivada aumente, chegando a ocupar cerca de $68 \%$ da área total cultivada com arroz irrigado no RS, como observado na safra 2013/2014 (CONAB, 2015).

O sistema de plantio pré-germinado é definido como um conjunto de técnicas de cultivo de arroz irrigado, adotadas em áreas sistematizadas, onde as sementes, previamente germinadas, são lançadas em quadros nivelados e inundados (Embrapa, 2005). Na entressafra, a área deve ser mantida a mais drenada possível. A prégerminação é feita pela imersão das sementes em água por 24 horas, acondicionadas em embalagens de polipropileno trançado. Após a hidratação, as sementes são colocadas à sombra por 24 a 36 horas, dependendo da temperatura do ar. As sementes devem ser umedecidas, sempre que for necessário, para ocorrer a pré-germinação. $O$ coleóptilo e a radícula deverão atingir de 2 a 3 milímetros para que a semeadura ocorra em solo com lâmina de água de 5 a 10 centímetros, sendo recomendado que se realize de dia, com mínimo vento e que a água dos quadros esteja limpa. No RS, em função do tamanho da lavoura, essa operação pode ser feita manualmente ou por meio de semeadoras a lanço ou por aviões agrícolas (Embrapa, 2005).

\subsection{Custos de Transação}

A abordagem teórica dos custos de transação está vinculada à Nova Economia Institucional (NEI), tendo Williamson (1985) como um dos principais expoentes. No entanto, essa abordagem teórica desenvolveu-se em decorrência dos estudos de Coase (1937), que propôs analisar a organização econômica em termos institucionais, 
A relação Custo/Volume/Lucro na Produção de Arroz: Um comparativo entre o cultivo prégerminado e o plantio direto

Cristiano Sausen Soares, Lucas Wancura Barbieri

considerando-se a firma e o mercado como meios alternativos de organização das transações. No entanto, verifica-se, nos estudos de Williamson, que os arranjos institucionais são inevitáveis à minimização dos custos, tanto de transação quanto de produção, sendo as transações internas resultado da comparação entre os custos internos da firma com os custos praticados no mercado (Vilpoux, 2011).

Nesse sentido, custos de transação podem ser definidos como associados à administração do sistema econômico, observados quando há diferenças entre os preços estimados pela organização com os preços praticados pelo mercado, o que significa que há eficiência nos custos da produção em algum componente desse mercado (Souza, Arbage, \& Corazza, 2006).

Diante disso, dentre as principais aplicações da teoria dos custos de transação, destaca-se a análise de organizações e grupos de empresa no âmbito dos negócios agroindustriais (Souza et al., 2006). Com base na abordagem teórica dos custos de transação, deve-se identificar os custos da atividade agrícola (Ferreira, Martins, Orlandi, \& Rocha Jr., 2015), cabendo sua utilização para análise dos custos da produção de arroz.

\subsection{Custos Agrícolas}

As operações de gestão agrária são consideradas sob três aspectos distintos: técnico, financeiro e econômico. O aspecto técnico tem por objetivo estudar a possibilidade de dada cultura na área rural, considerando questões de produtividade como solo e sementes. No tocante ao aspecto financeiro, são consideradas as entradas e saídas de recursos financeiros para manter o equilíbrio do negócio. Já quanto ao aspecto econômico, são observados os custos e os resultados das atividades (Valle, 1987).

O custo da produção agrícola é a soma dos valores de todos os recursos (insumos e serviços) utilizados no processo produtivo de uma atividade agrícola, em dado período, podendo ser classificados como de curto ou longo prazo (CONAB, 2015). De acordo com a CONAB (12015), a estimativa dos custos está ligada à gestão da 
A relação Custo/Volume/Lucro na Produção de Arroz: Um comparativo entre o cultivo prégerminado e o plantio direto

Cristiano Sausen Soares, Lucas Wancura Barbieri

tecnologia, ou seja, à alocação eficiente dos recursos produtivos e ao conhecimento dos preços.

Segundo Hillmann (2001), é fundamental conhecer os custos de transação e produção, bem como as possibilidades de reduzi-los, visto que commodities não podem redefinir seus preços de acordo com seus custos, mas, sim, adequar seus custos a partir dos preços de mercado. Dessa forma, poderia ser utilizada a técnica do custo meta para sua apuração, porém Carastan (1999) afirma que suas bases não estão fixadas em aspectos científicos, tampouco contidas nas teorias da contabilidade de custos, sendo realizadas estimativas pelo setor de produção, considerando as restrições do mercado com base nos preços praticados e na rentabilidade desejada. Assim, outras alternativas podem ser encontradas com base na literatura acerca do tema, sendo necessário conhecer alguns termos e conceitos para sua aplicação.

Para compreender a terminologia aplicada à contabilidade de custos, apresentase o Quadro 1 com alguns termos utilizados e suas definições, conforme Martins (2006).

\begin{tabular}{|l|l|}
\hline Gasto & $\begin{array}{l}\text { "Compra de um produto ou serviço qualquer, que gera sacrifício financeiro para a } \\
\text { entidade (desembolso), sacrifício esse representado por entrega ou promessa de entrega } \\
\text { de ativos (normalmente dinheiro)" (p. 24). }\end{array}$ \\
\hline Desembolso & "Pagamento resultante da aquisição do bem ou serviço" (p. 25). \\
\hline Investimento & $\begin{array}{l}\text { "Gasto ativado em função de sua vida útil ou de benefícios atribuíveis a futuro(s) } \\
\text { período(s)" (p. 25). }\end{array}$ \\
\hline Custo & $\begin{array}{l}\text { "Gasto relativo a bem ou serviço utilizado na produção de outros bens ou serviços" (p. } \\
25)\end{array}$ \\
\hline Despesa & "Bem ou serviço consumido direta ou indiretamente para a obtenção de receitas" (p. 25). \\
\hline Perda & "Bem ou serviço consumidos de forma anormal e involuntária" (p. 25). \\
\hline
\end{tabular}

\section{Quadro 1.Terminologias da contabilidade de custos}

Fonte: Adaptado de Martins (2006).

Além dos termos mencionados no Quadro 1, outras terminologias são empregadas a partir da classificação dos custos. Assim, Martins (2006) destaca que os custos podem ser classificados sob dois aspectos: conforme a identificação com o produto ou serviço e segundo o volume ou quantidade. 
A relação Custo/Volume/Lucro na Produção de Arroz: Um comparativo entre o cultivo prégerminado e o plantio direto Cristiano Sausen Soares, Lucas Wancura Barbieri

A classificação dos custos, de acordo com a identificação com a produção, se dá entre Custos Diretos e Custos Indiretos. Os custos diretos "são identificados com precisão no produto acabado, através de um sistema e um método de medição, cujo valor é relevante" (Santos, Marion, \& Segatti, 2008). Os autores citam como exemplos os valores de horas de mão de obra direta, quilos de sementes (plantio agrícola), gastos com funcionamento e manutenção de tratores, etc. Já os custos indiretos "são aqueles necessários à produção, geralmente de um mix de produtos, mas alocáveis arbitrariamente, através de um sistema de rateio, estimativas e outros meios" (Santos et al. 2008). Para os autores, os salários dos técnicos e outros gastos necessários à produção, sem relação direta com o produto ou serviço específico, são exemplos de custos indiretos.

A partir do volume da produção, os custos são classificados como Variáveis ou Fixos. Os custos variáveis "são aqueles que variam em proporção direta com o volume de produção ou área de plantio" (Santos et al. 2008). Como exemplos, podem ser citados a mão de obra direta, materiais diretos, horas-máquina, dentre outros. Os custos fixos "são aqueles que permanecem inalterados em termos físicos e de valor, independentemente do volume de produção e dentro de um intervalo de tempo relevante. Geralmente são oriundos da posse de ativos e de capacidade ou estado de prontidão para produzir" (Santos et al., 2008). Os autores destacam os valores de depreciação das instalações e máquinas agrícolas como exemplo.

Os termos e conceitos aplicados à contabilidade de custos apresentados são fundamentais para a correta utilização e análise das informações geradas a partir da implantação de métodos de custeio. Conforme Martins (2006), "Custeio significa Apropriação de Custos". Com isso, existem alguns métodos para apropriar os custos aos produtos ou serviços, destacando-se o Custeio por Absorção, Custeio Direto ou Variável, Custeio ABC e o Custeio Pleno ou RKW.

O Custeio por Absorção consiste na apropriação de todos os custos de produção aos produtos; todos os gastos relativos à produção são distribuídos aos produtos ou serviços (Martins, 2006). Para a apropriação dos custos, se faz a separação das 
A relação Custo/Volume/Lucro na Produção de Arroz: Um comparativo entre o cultivo prégerminado e o plantio direto

Cristiano Sausen Soares, Lucas Wancura Barbieri

despesas, pois estão relacionadas à geração de receita e são lançadas na demonstração de resultado do exercício, enquanto os custos são apropriados aos produtos (Megliorini, 2012).

O Custeio baseado em atividades $(A B C)$ é uma ferramenta que possibilita melhor visualização dos custos de produtos e serviços, mediante análise das atividades executadas para a sua produção. Com o avanço tecnológico e a crescente complexidade dos sistemas de produção, em muitas indústrias os custos indiretos vêm aumentando continuamente, tanto em valores absolutos quanto em termos relativos, comparativamente aos custos diretos (Martins, 2006).

A característica principal do custeio direto ou variável é a identificação dos custos vinculados com as atividades produtivas e que sejam variáveis em determinada medida, enquanto os custos fixos são desconsiderados como custos e são descontados diretamente no resultado do período (Leone, 2000).

Pela própria natureza dos custos fixos, arbitrariedade em seu rateio e variação por unidade em função de oscilações do volume global e por propiciar valores de lucro não muito úteis para fins decisórios, criou-se um critério alternativo ao Custeio por Absorção. "Trata-se do Custeio Variável (ou Custeio Direto), em que só são agregados aos produtos seus custos variáveis, considerando-se os custos fixos como se fossem despesas" (Martins, 2006).

Conforme Backes, Kuhn, Perleberg, Dalben, Wiest e Alberti (2007), a forma de apropriação dos gastos no método de custeio pleno ou RKW é semelhante ao custeio por absorção, mas considerando a despesa. No custeio pleno, utiliza-se a apropriação de todos os gastos aos produtos, sendo seu objetivo essencialmente gerencial, enquanto que, no custeio por absorção, alocam-se apenas os custos, em que seu objetivo é financeiro, visando à valoração de estoques e à apuração do resultado.

Para identificar, dentre os métodos de custeio, aquele considerado adequado aos objetivos do estudo, realizou-se um levantamento de artigos publicados de 2004 a 2014, nos periódicos dedicados ao agronegócio e nos Anais dos Congressos Brasileiros de Custos, tendo como busca as palavras-chave "apuração de custos" e 
A relação Custo/Volume/Lucro na Produção de Arroz: Um comparativo entre o cultivo prégerminado e o plantio direto

Cristiano Sausen Soares, Lucas Wancura Barbieri

"arroz". Os artigos selecionados justificam-se por estarem relacionados ao tema em estudo, sendo apresentados no Quadro 2.

\begin{tabular}{|c|c|c|c|}
\hline Título & Autores & Revista/Congresso & $\begin{array}{l}\text { Método de } \\
\text { custeio }\end{array}$ \\
\hline $\begin{array}{l}\text { Análise dos custos de produção, da } \\
\text { produtividade e da rentabilidade em } \\
\text { relação a três tecnologias de cultivo de } \\
\text { arroz irrigado na fazenda São } \\
\text { Sebastião, Querência do Norte/PR }\end{array}$ & Bassani \& Breda, 2012 & $\begin{array}{l}\text { Custos } \quad e \\
\text { @gronegócio online }\end{array}$ & $\begin{array}{l}\text { Custeio } \\
\text { Direto }\end{array}$ \\
\hline $\begin{array}{l}\text { Avaliação do custo de produção de } \\
\text { arroz em pequenas propriedades rurais } \\
\text { do Rio Grande do Sul: Um estudo de } \\
\text { caso }\end{array}$ & $\begin{array}{l}\text { Borges, Mainardi \& } \\
\text { Velasquez, } 2013\end{array}$ & $\begin{array}{l}\text { Agronegócios } \\
\text { Meio Ambiente }\end{array}$ & $\begin{array}{l}\text { Custeio por } \\
\text { Absorção }\end{array}$ \\
\hline $\begin{array}{l}\text { Custo total do beneficiamento do arroz } \\
\text { em uma cooperativa agrícola }\end{array}$ & $\begin{array}{l}\text { Velasquez, Santos \& } \\
\text { Borges, } 2012\end{array}$ & $\begin{array}{ll}\text { XIX } & \text { Congresso } \\
\text { Brasileiro de Custos }\end{array}$ & $\begin{array}{l}\text { Custeio por } \\
\text { Absorção }\end{array}$ \\
\hline $\begin{array}{l}\text { Diferenciais de custos em culturas de } \\
\text { arroz: A experiência do Rio Grande do } \\
\text { Sul }\end{array}$ & $\begin{array}{l}\text { Brondani, Madruga, de } \\
\text { Lima Trindade \& } \\
\text { Venturini, 2006 }\end{array}$ & Universo Contábil & $\begin{array}{l}\text { Custeio } \\
\text { Direto }\end{array}$ \\
\hline $\begin{array}{l}\text { Rizicultura Mutagênica: Diferenciação } \\
\text { de custos do plantio convencional e } \\
\text { direto }\end{array}$ & $\begin{array}{l}\text { Venturini, } \quad \text { Brondani, } \\
\text { Madruga, Costa \& } \\
\text { Trindade, } 2006\end{array}$ & $\begin{array}{ll}\text { XIII } & \text { Congresso } \\
\text { Brasileiro de Custos }\end{array}$ & $\begin{array}{l}\text { Custeio } \\
\text { Direto }\end{array}$ \\
\hline $\begin{array}{l}\text { Aplicação do método de custeio RKW } \\
\text { em uma cooperativa agrícola }\end{array}$ & $\begin{array}{lr}\text { Backes, } & \text { Kuhn, } \\
\text { Perleberg, } & \text { Dalben, } \\
\text { Wiest \& Alberti } & (2007) .\end{array}$ & 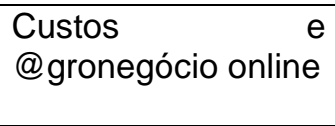 & $\begin{array}{c}\text { Custeio } \\
\text { RKW/Pleno }\end{array}$ \\
\hline
\end{tabular}

Quadro 2. Métodos de Custeio aplicados a outras pesquisas

Fonte: Dados da pesquisa.

Foram identificadas três pesquisas que utilizaram o método de custeio direto, enquanto outros dois trabalhos adotaram o método de custeio por absorção, e um estudo utilizou o método de custeio Pleno (RKW). Não foram identificados estudos com a adoção de outros métodos de custeio. Assim, corroborando com os autores referenciados, identificou-se o método de custeio direto como aquele que mais vezes foi utilizado para apuração dos custos agrícolas, servindo de modelo a ser adotado no presente estudo de caso para análise da relação custo/volume/lucro. 
A relação Custo/Volume/Lucro na Produção de Arroz: Um comparativo entre o cultivo prégerminado e o plantio direto Cristiano Sausen Soares, Lucas Wancura Barbieri

\subsection{Relação Custo/Volume/Lucro}

A análise custo/volume/lucro está intimamente relacionada ao uso de sistemas de custos para o auxílio na tomada de decisões de curto prazo, característica apontada ao custeio direto (Bornia, 2002). De acordo com Bomfim e Passarelli (2006), essa relação "examina o impacto nos lucros de alterações nos custos e despesas variáveis, custos e despesas fixas, preço de venda, volume e diversidade de produtos".

A informação gerada a partir da relação custo/volume/lucro é de grande valia a qualquer tipo de empresa ou atividade, pois, com seus conceitos, é possível verificar e comparar os resultados da produção entre diferentes tipos de processos produtivos ou produtos. Assim, mesmo com os gastos sendo mais elevados, o volume da produção e o lucro são variáveis que apontarão qual processo ou produto é mais eficiente.

Dessa forma, segundo Callado, Albuquerque e Silva (2007), para a utilização do sistema de análise custo/volume/lucro, é necessário considerar os custos e despesas variáveis e os custos e despesas fixas, além de conhecer alguns conceitos básicos relacionados a Margem de Contribuição (MC) e Ponto de Equilíbrio (PE).

A partir da adoção do custeio direto, a Margem de Contribuição pode ser entendida como a parcela do preço de venda que excede os custos e despesas variáveis e que serve para contribuir com a quitação dos custos e despesas fixas (Perez Jr., Oliveira, \& Costa, 2012). Nesse contexto, quando a Margem da Contribuição se iguala aos custos e despesas fixas, tem-se o Ponto de Equilíbrio (Megliorini, 2012).

Segundo Warren, Reeve e Fess (2001), "o ponto de equilíbrio é o nível de operações no qual as receitas e os custos de uma empresa são exatamente iguais. Em equilíbrio, uma empresa não tem lucro nem prejuízo operacional". Ainda, para Martins (2006), o ponto de equilíbrio também pode ser utilizado para análise da situação econômica e financeira da organização ou atividade.

Nesse contexto, dependendo das decisões a serem tomadas, existem ao menos três tipos de Pontos de Equilíbrio (Megliorini, 2012): Ponto de Equilíbrio Contábil - PEC (as receitas se igualam aos custos e despesas totais); Ponto de Equilíbrio Econômico PEE (quando a margem de contribuição dos produtos vendidos cobre o custo de 
A relação Custo/Volume/Lucro na Produção de Arroz: Um comparativo entre o cultivo prégerminado e o plantio direto

Cristiano Sausen Soares, Lucas Wancura Barbieri

oportunidade do capital investido); Ponto de Equilíbrio Financeiro (quando o valor das disponibilidades permanece inalterado, independentemente de haver resultado contábil ou econômico negativo).

Wernke (2001) destaca que a análise custo/volume/lucro é um instrumento gerencial que visa demonstrar, por meio de fórmulas matemáticas e gráficos, as interrelações existentes entre as vendas, os custos fixos e variáveis, o nível de atividade desenvolvido e o lucro alcançado ou desejado, considerando a margem de contribuição e o ponto de equilíbrio.

\section{METODOLOGIA}

A pesquisa classifica-se, de acordo com o problema, como qualitativa. Conforme Richardson (1999), "os estudos que empregam uma metodologia qualitativa podem descrever a complexidade do problema, analisar a interação das variáveis, compreender e classificar processos dinâmicos vividos por grupos sociais".

No tocante aos objetivos, a pesquisa classifica-se como descritiva. Richardson (1999) afirma que a pesquisa descritiva aponta características de determinada população ou fenômeno ou estabelecimento de relações entre variáveis.

Em se tratando dos procedimentos adotados nesta pesquisa, apresenta-se o estudo de caso, aliado à pesquisa documental. Yin (2001) destaca o estudo de caso como método de pesquisa em profundidade, sendo observados aspectos com maior robustez e proximidade.

A escolha do caso se deve ao fato de o produtor rural realizar o plantio de arroz com duas técnicas distintas de cultivo na mesma propriedade, controlando seus gastos por tipo de cultivo, o que possibilitou a análise. Ressalta-se que os dois métodos de cultivo foram utilizados simultaneamente na propriedade, onde as condições climáticas e de solo foram as mesmas para ambos os métodos de cultivo, não sendo considerados seus impactos nesse estudo. 
A relação Custo/Volume/Lucro na Produção de Arroz: Um comparativo entre o cultivo prégerminado e o plantio direto Cristiano Sausen Soares, Lucas Wancura Barbieri

A coleta dos dados se deu por meio da análise documental e entrevistas semiestruturadas com os principais atores envolvidos no processo produtivo (o agrônomo responsável pela lavoura, o produtor rural e o representante da EMATER/RS que assessora o produtor).

As entrevistas abordaram o perfil dos respondentes e informações sobre suas experiências com os processos produtivos, estrutura de gastos, bem como o cenário atual da rizicultura. A análise dessas informações foi realizada individualmente, buscando-se termos comuns para traçar o comportamento das variáveis consideradas neste estudo.

A partir dos dados coletados nas entrevistas e nos documentos analisados, foi possível identificar os gastos da produção de arroz da propriedade rural, relativos à safra 2013/2014, sendo utilizados, como fonte, o Livro Caixa do Produtor Rural, as Notas Fiscais, os Recibos e Folhas de Pagamento, além de outros documentos registrados, já segregados por método produtivo.

Para a realização das análises, utilizou-se a sistemática da relação custo/volume/lucro, onde é realizada a comparação das variáveis em termos proporcionais dos "custos de produção", "volume produzido" e o "resultado gerado" para os dois métodos de cultivo utilizados na propriedade.

\section{RESULTADOS E DISCUSSÕES}

Para redução dos custos de transação, a maioria dos produtores rurais é associada às cooperativas agrícolas, tanto para produção como para comercialização. No entanto, existem aqueles que possuem maquinário e estrutura de secagem própria. Nessas condições, identificou-se a propriedade rural localizada na cidade de Cacequi/RS, que utiliza dois métodos de cultivo de arroz, controlando seus gastos separadamente, na busca de melhores resultados.

Com área total arrendada de 236 hectares, a propriedade rural utiliza 205 hectares como área total para o cultivo de arroz. Nela, a semeadura foi realizada em 
A relação Custo/Volume/Lucro na Produção de Arroz: Um comparativo entre o cultivo prégerminado e o plantio direto Cristiano Sausen Soares, Lucas Wancura Barbieri

duas áreas distintas, sendo utilizados 27 hectares com o plantio direto (13\%) e 178 hectares com o plantio pré-germinado (87\%). A propriedade possui dois funcionários prestando serviços durante o ano todo e não apenas no período do plantio e colheita, sendo contratados mais dois temporários na época de safra. O produtor conta ainda com um engenheiro agrônomo que presta assistência à propriedade, além da assessoria da EMATER/RS.

O agricultor possui mais de trinta anos de experiência no cultivo de arroz. Conforme suas informações, já foram utilizados todos os métodos de cultivo atestados pela EMATER/RS, sendo identificados os métodos de cultivo direto e pré-germinado como aqueles que apresentam melhor aproveitamento na área. Porém, até o momento, não há informações registradas pelo produtor que pudessem comprovar essa afirmação. Desse modo, a gestão da produção de arroz na propriedade está embasada na percepção do produtor rural.

\subsection{Processos Produtivos}

Para a utilização do plantio direto, o produtor inicia o preparo do solo após a colheita anterior, passando na terra o "rolo faca" (implemento que tem o objetivo de afundar a palha que sobrou e emparelhar o solo). Depois, são cavadas valetas para que a água escoe e a área fique seca a ponto de não formar acúmulos no solo. Após, transcorre um período de descanso da terra de aproximadamente seis meses, com a finalidade de emparelhar e nivelar o solo. A seguir, são realizadas taipas para condução da água, e a terra é dessecada para eliminar todas as ervas e gramas. Finalizando, são plantadas as sementes para germinação e desenvolvimento do arroz, sendo aplicado o herbicida, a ureia e a água no solo. Passado um período de pouco mais de três meses para o crescimento e amadurecimento do arroz, o produto pode ser colhido.

No plantio pré-germinado, utiliza-se o "rolo faca" e as valetas para secar o solo de maneira idêntica, como ocorre no método do plantio direto. A primeira diferença surge quanto ao período de descanso da terra, que, no pré-germinado, é de quatro meses. Após o descanso, são utilizados os discos hidráulicos na terra seca para limpar 
A relação Custo/Volume/Lucro na Produção de Arroz: Um comparativo entre o cultivo prégerminado e o plantio direto

Cristiano Sausen Soares, Lucas Wancura Barbieri

o solo. Na sequência, a água é colocada nos quadros, e utilizam-se os discos hidráulicos na terra, agora encharcada, fazendo um lodo. Depois de passada a plaina, as sementes são postas em sacos e depositadas em tanques cheios de água e, passado um dia, são colocadas em galpões e cobertas com lona para germinar e posteriormente semeá-las na terra encharcada, sendo aplicadas duas camadas de ureia. Por fim, aguarda-se o crescimento e amadurecimento do arroz por quatro meses para colheita.

O Quadro 3 apresenta as diferenças entre o plantio direto e o pré-germinado.

\begin{tabular}{|l|l|l|}
\hline \multicolumn{1}{|c|}{ Fatores } & \multicolumn{1}{|c|}{ Plantio Direto } & \multicolumn{1}{c|}{ Pré-germinado } \\
\hline Tempo de preparo do solo & 3 meses geses \\
\hline Técnica de plantio & Sementes enterradas no solo & $\begin{array}{l}\text { Sementes germinadas são } \\
\text { lançadas nos quadros já } \\
\text { completos com água. }\end{array}$ \\
\hline Utilização de herbicida & Utiliza & Não utiliza. \\
\hline Formato do terreno & $\begin{array}{l}\text { Taipas (curvas de nível) } \\
\text { utilizadas para condução de } \\
\text { água }\end{array}$ & $\begin{array}{l}\text { Quadrados ou retângulos onde } \\
\text { são completados com água }\end{array}$ \\
\hline $\begin{array}{l}\text { Tempo em que o solo fica } \\
\text { submerso }\end{array}$ & 3 meses & 5 meses \\
\hline Tempo total & 11 meses & 10 meses \\
\hline
\end{tabular}

Quadro 3. Diferenças entre os Cultivos Plantio Direto e o Pré-germinado

Fonte: Dados da pesquisa.

Para o plantio, manutenção e colheita da safra, independentemente do método de cultivo, os gastos ocorridos afetam o resultado, e a forma de acumulação dos custos pode interferir neste resultado, cabendo identificar quais são esses gastos e definir a forma de apropriá-los.

\subsection{Apuração dos Custos}

Considerando os métodos de cultivo adotados na safra 2013/2014 e os documentos e relatórios de controles de gastos fornecidos pelo produtor rural, foram calculados, com base no método de custeio direto, os custos da safra. 
A relação Custo/Volume/Lucro na Produção de Arroz: Um comparativo entre o cultivo prégerminado e o plantio direto

Cristiano Sausen Soares, Lucas Wancura Barbieri

A Tabela 1 apresenta os valores aplicados na produção de arroz com a utilização do plantio pré-germinado.

Tabela 1

Levantamento dos Custos Diretos no Plantio Pré-Germinado

\begin{tabular}{|l|l|l|c|c|}
\hline \multicolumn{1}{|c|}{ Custo Direto Total } & \multicolumn{1}{|c|}{ Unidade } & \multicolumn{1}{c|}{ Gastos (R\$) } & Total (R\$) & \% \\
\hline 1- Preparo do Solo & - & - & $14.558,80$ & $21,60 \%$ \\
\hline 1.1 Rolo Faca & 18 dias & $3.514,50$ & - & \\
\hline 1.2 Drenagem do Solo & 2 dias & 276,90 & - & \\
\hline 1.3 Disco Hidráulico & 24 dias & $8.179,20$ & - & \\
\hline 1.4 Plaina & 10 dias & $1.704,00$ & - & \\
\hline 1.5 Semeadura & 20 dias & 383,40 & - & \\
\hline 1.6 Aplicação de Ureia & 4 dias & 500,80 & - & \\
\hline 2- Colheita & 27 dias & $13.802,40$ & $13.802,40$ & $20,48 \%$ \\
\hline 3- Sementes & 463 sacos & $27.780,00$ & $27.780,00$ & $41,22 \%$ \\
\hline 4- Ureia & 712 sacos & $39.160,00$ & $39.160,00$ & $58,11 \%$ \\
\hline 5- Mão de obra temporária & - & $6.000,00$ & $6.000,00$ & $8,90 \%$ \\
\hline 6- Fogos de Artifício & - & $3.000,00$ & $3.000,00$ & $4,45 \%$ \\
\hline 7- Agrotóxico & - & 400,00 & 400,00 & $0,59 \%$ \\
\hline 8 - Energia Elétrica & - & $15.259,78$ & $15.259,78$ & $22,64 \%$ \\
\hline \multicolumn{2}{|l|}{ Total = Área Cultivada (178 hectares) } & $119.960,98$ & $100,00 \%$ \\
\hline Custo Direto por Hectare & & 673,94 & \\
\hline
\end{tabular}

Nota. Fonte: Dados da pesquisa.

No plantio pré-germinado, a passada do rolo faca teve duração de dezoito dias e um gasto de $R \$ 3.514,50$. Este resultado foi encontrado com base no consumo diário de óleo diesel dos tratores. Os procedimentos seguintes fazem parte do preparo do solo: drenagem do solo, disco hidráulico, plaina, semeadura e a aplicação de ureia, encontrando-se o total de $R \$ 14.558,80$ (21,60\% do custo direto total). A colheita foi calculada da mesma forma, encontrando-se o valor de $R \$ 13.802,40(20,48 \%$ do total dos custos diretos). O valor das sementes foi calculado de acordo como número de sacos que foram adquiridos, multiplicado pelo valor de compra ( $R \$ 60,00$ a unidade), totalizando $\mathrm{R} \$ 27.780,00$ (41,22\% do total dos custos diretos). Já a ureia foi adquirida a $\mathrm{R} \$ 55,00$ o saco, totalizando $\mathrm{R} \$ 39.160,00$ (58,11\% do total dos custos diretos). 
A mão de obra temporária apresentou um gasto de $\mathrm{R} \$ 6.000,00$, incluindo-se os encargos, conforme informações extraídas da folha de pagamento. Os fogos de artifício são gastos para espantar os patos e aves que ficam nos quadros de água e estragam o arroz ainda novo, para o que se gastaram $R \$ 3.000 .00$. O agrotóxico tem um custo relativamente baixo ( $R \$ 400,00)$, pois é pouca a quantidade utilizada, e ele é posto na forma de "benzedura", que consiste na técnica de colocar o produto na entrada de água dos quadros, assim se espalhando por todo ele. Este gasto apresenta a menor representatividade frente ao custo total $(0,59 \%)$.

O último item de gastos do método de cultivo pré-germinado é a energia elétrica utilizada para o funcionamento do motor que bombeia água para a lavoura. Esse custo é apurado a partir do período de utilização da água no pré-germinado (cinco meses). No entanto, nos três meses em que seu uso ocorre para os dois cultivos, o produtor estima um gasto proporcional ao tempo de uso em cada tipo de cultivo, sendo $70 \%$ no pré-germinado e $30 \%$ no plantio direto, chegando o valor do gasto no pré-germinado a $\mathrm{R} \$ 15.259,78$, representando $22,64 \%$ no total dos custos diretos. Assim, para a safra $2013 / 2014$, o custo total do plantio pré-germinado foi de $R \$ 119.960,98$, enquanto o custo por hectare foi de $\mathrm{R} \$ 673,94$, dividindo-se o custo total pela área utilizada nesse cultivo.

Em relação ao plantio direto, conforme a Tabela 2, o preparo do solo contém sete etapas que, juntas, formaram um custo de $\mathrm{R} \$ 2.875,50$ (10,09\% do custo direto total). 
A relação Custo/Volume/Lucro na Produção de Arroz: Um comparativo entre o cultivo prégerminado e o plantio direto Cristiano Sausen Soares, Lucas Wancura Barbieri

Tabela 2

Levantamento dos Custos Diretos no Plantio Direto

\begin{tabular}{|c|c|c|c|c|}
\hline Custo direto total & Unidade & Gastos (R\$) & Total (R\$) & $\%$ \\
\hline 1- Preparo do Solo & - & - & $2.875,50$ & $10,09 \%$ \\
\hline 1.1 Rolo Faca & 2 dias & 383,40 & - & \\
\hline 1.2 Drenagem do Solo & 1 dia & 63,90 & - & \\
\hline 1.3 Remaplan/plaina & 4dias & 852,00 & - & \\
\hline 1.4 Taipas & 2 dias & 426,00 & - & \\
\hline 1.5 Aplicação de dessecante & 1 dia & 149,10 & - & \\
\hline 1.5 Plantio & 2 dias & 639,00 & - & \\
\hline 1.6 Aplicação de herbicida & 1 dia & 149,10 & - & \\
\hline 1.7 Aplicação de Ureia & 1 dia & 213,00 & - & \\
\hline 2- Colheita & 3 dias & $1.533,60$ & $1.533,60$ & $5,38 \%$ \\
\hline 3- Sementes & 180 sacos & $10.800,00$ & $10.800,00$ & $37,88 \%$ \\
\hline 4- Ureia & 108 sacos & $5.940,00$ & $5.940,00$ & $20,83 \%$ \\
\hline 5- Herbicida & - & 982,20 & 982,20 & $3,45 \%$ \\
\hline 6 - Energia Elétrica & - & $4.423,29$ & $4.423,29$ & $15,51 \%$ \\
\hline 7 - Dessecante & - & $1.956,15$ & $1.956,15$ & $6,86 \%$ \\
\hline \multicolumn{3}{|c|}{ Total = Área Cultivada (27 hectares) } & $28.510,74$ & $100,00 \%$ \\
\hline \multicolumn{3}{|l|}{ Custo Direto por Hectare } & $1.055,95$ & \\
\hline
\end{tabular}

Nota. Fonte: Dados da pesquisa.

Neste plantio, algumas etapas são idênticas ao pré-germinado (como o rolo faca e a drenagem do solo), sendo apurado seu gasto a partir do consumo diário de óleo diesel e seu preço, assim como na fase da colheita. Para as sementes e a ureia, é utilizado o preço unitário para aplicação nos dois métodos de plantio, mas no direto a representatividade dos gastos com as sementes é de $37,88 \%(R \$ 10.800,00)$ e com a ureia de 20,83\% ( $R \$ 5.940,00)$. Neste cultivo, o custo com herbicida teve maior representatividade que no cultivo pré-germinado, ficando com $3,45 \%$ do custo direto total $(\mathrm{R} \$ 982,20)$. Além dessas etapas, o plantio direto apresenta o uso de dessecante, com valor de $\mathrm{R} \$ 1.956,15$ (6,86\% do custo direto total). Para o custo com energia elétrica no cultivo direto, utilizou-se o período de três meses e, conforme o produtor, $30 \%$ do gasto total de energia, pois, nesse período, é utilizado o bombeamento da água nos dois sistemas de cultivo. O custo da energia no plantio direto apurado foi de $R \$$ $4.423,39(15,52 \%$ do custo direto total). 
A relação Custo/Volume/Lucro na Produção de Arroz: Um comparativo entre o cultivo prégerminado e o plantio direto

Cristiano Sausen Soares, Lucas Wancura Barbieri

Com esses dados, apurou-se o custo direto total pelo plantio direto, chegando ao total de $\mathrm{R} \$ 28.510,74$. Para apurar o custo por hectare, dividiu-se o valor do custo direto total pela área utilizada, apurando-se o valor de $R \$ 1.055,95$ por hectare, apresentando uma diferença de $\mathrm{R} \$ 382,01$ a maior no comparativo com o custo do cultivo prégerminado.

Esse resultado demonstra que, ao utilizar o plantio direto, o produtor pode ter um custo mais elevado, se comparado com o plantio pré-germinado. Esses resultados corroboram os achados de Brondani et al. (2006), que apurou um custo por hectare no plantio direto com irrigação mecânica de $R \$ 1.365,40$, apresentando uma diferença de $\mathrm{R} \$ 52,15$ em relação ao custo apurado no método pré-germinado.

\subsection{Relação Custo/Volume/Lucro}

Apurado o custo direto por hectare de cada método de plantio, coube identificar os demais custos que afetam o resultado. Desse modo, foram relacionados os bens utilizados na atividade para apuração da depreciação.

No entanto, a maioria dos bens utilizados na produção rural não possuía registro das informações que viabilizassem o cálculo da depreciação. Dessa forma, fez-se necessário realizar uma estimativa por meio de uma (re)avaliação dos bens, com base nos conhecimentos do produtor rural e de um engenheiro mecânico que presta assistência ao produtor, considerando-se o ano, marca e modelo do bem, estado de conservação, tempo de uso e histórico de manutenção, tendo por base o valor de mercado. Ao apontar o estado de conservação do bem, estimou-se sua vida útil para a atividade, a partir de 2014, e seu valor de mercado.

A Tabela 3 apresenta os bens utilizados na produção e os dados para apuração da depreciação. 
A relação Custo/Volume/Lucro na Produção de Arroz: Um comparativo entre o cultivo prégerminado e o plantio direto Cristiano Sausen Soares, Lucas Wancura Barbieri

Tabela 3

Levantamento da depreciação anual dos implementos

\begin{tabular}{|l|c|c|c|c|}
\hline \multicolumn{1}{|c|}{ Implemento } & $\begin{array}{c}\text { Valor } \\
\text { Avaliado (R\$) }\end{array}$ & $\begin{array}{c}\text { Vida Útil } \\
\text { (anos) }\end{array}$ & $\begin{array}{c}\text { Valor Residual } \\
\text { (R\$) }\end{array}$ & $\begin{array}{c}\text { Depreciação } \\
\text { anual (R\$) }\end{array}$ \\
\hline 01 Motor Elétrico GE de 50 CV & $8.000,00$ & 10 & 800,00 & 720,00 \\
\hline 01 Rolo-faca BALDAN & $9.500,00$ & 10 & 950,00 & 855,00 \\
\hline 01 Trator MF 4275 & $70.000,00$ & 10 & $7.000,00$ & $6.300,00$ \\
\hline 01 Semeadeira Adubadeira & $5.500,00$ & 10 & 550,00 & 495,00 \\
\hline 02 Grades Niveladoras BALDAN & $7.200,00$ & 5 & 720,00 & $1.296,00$ \\
\hline 01 Trator MF 292 & $50.000,00$ & 10 & $5.000,00$ & $4.500,00$ \\
\hline 01 Plaina BALDAN & $3.000,00$ & 10 & 300,00 & 270,00 \\
\hline 01 Pulverizador Agrícola JACTO & $5.500,00$ & 10 & 550,00 & 495,00 \\
\hline 01 Plantadeira SEMEATO TDNG 320 & $22.000,00$ & 7 & $2.200,00$ & $2.828,57$ \\
\hline 01 Remaplan AGRIMEC & $3.000,00$ & 10 & 300,00 & 270,00 \\
\hline 01 Silo secador & $170.000,00$ & 20 & $17.000,00$ & $5.100,00$ \\
\hline 01 Colheitadeira MF 3640 & $88.000,00$ & 10 & $8.800,00$ & $7.920,00$ \\
\hline 01 Entaipadeira SEMEATO TS 14 & $8.500,00$ & 10 & 850,00 & 765,00 \\
\hline 01 Colheitadeira MF 3640 & $86.000,00$ & 10 & $8.600,00$ & $7.740,00$ \\
\hline 01 Graneleiro JACUÍ & $8.000,00$ & 10 & 800,00 & 720,00 \\
\hline 02 Graneleiros ABICHIT & $10.000,00$ & 10 & $1.000,00$ & 900,00 \\
\hline 01 Trator MF 295 & $40.000,00$ & 8 & $4.000,00$ & $4.500,00$ \\
\hline 01 Trator MF 290 & $25.000,00$ & 7 & $2.500,00$ & $3.214,29$ \\
\hline 01 Gaminhão Ford & $20.000,00$ & 5 & $2.000,00$ & $3.600,00$ \\
\hline & & & & $52.488,86$ \\
\hline
\end{tabular}

Nota. Fonte: Dados da pesquisa.

Dentre as máquinas agrícolas utilizadas na produção, a que apresentou maior depreciação é a colheitadeira MF 3640, adquirida no ano 1992, cujo valor reavaliado encontrou uma depreciação de $\mathrm{R} \$ 7.920,00$ por ano. Os implementos com menor depreciação são a plaina e a remaplan, ambos com $\mathrm{R} \$ 270,00$ anuais. A depreciação total apurada é de $\mathrm{R} \$ 52.488,86$ por ano.

Com base na apuração da depreciação, considerou-se que os bens são utilizados nos dois métodos de cultivo, sendo estimada sua proporcionalidade a partir da área cultivada ( $87 \%$ no cultivo pré-germinado e $13 \%$ no plantio direto), sendo este um custo conjunto da atividade. De acordo com Martins (2006), os custos conjuntos podem ser distribuídos aos produtos com base na receita total, no lucro estimado ou na quantidade produzida. No entanto, para fins de comparação entre os dois tipos de 
A relação Custo/Volume/Lucro na Produção de Arroz: Um comparativo entre o cultivo prégerminado e o plantio direto

Cristiano Sausen Soares, Lucas Wancura Barbieri

cultivo, optou-se por manter a forma de distribuição com base na área cultivada, assim como foram tratados os demais custos conjuntos: despesas com funcionários, arrendamento, juros sobre financiamento e despesas de estocagem.

A partir de então, apurou-se o resultado da safra, segregado por método de plantio, conforme apresentado na Tabela 4.

Tabela 4

Levantamento dos Resultados do Período (R\$)

\begin{tabular}{|l|c|c|c|c|c|c|c|c|}
\hline & $\begin{array}{c}\text { Plantio } \\
\text { Pré- } \\
\text { Germinado }\end{array}$ & $\begin{array}{c}\text { AV } \\
\mathbf{( \% )}\end{array}$ & $\begin{array}{c}\text { AH } \\
\mathbf{( \% )}\end{array}$ & $\begin{array}{c}\text { Plantio } \\
\text { Direto }\end{array}$ & $\begin{array}{c}\text { AV } \\
\mathbf{( \% )}\end{array}$ & $\begin{array}{c}\text { AH } \\
\text { (\%) }\end{array}$ & $\begin{array}{c}\text { TOTAL } \\
\text { (R\$) }\end{array}$ & AV (\%) \\
\hline Receita & $447.848,00$ & 100,00 & 89,00 & $57.834,00$ & 100,00 & 11,00 & $505.682,00$ & 100,00 \\
\hline CPV & $119.960,98$ & 26,79 & 81,00 & $28.510,74$ & 49,30 & 19,00 & $148.471,72$ & 29,36 \\
\hline MC & $327.887,02$ & 73,21 & 92,00 & $29.323,26$ & 50,70 & 8,00 & $357.210,28$ & 70,64 \\
\hline CF e DF & $189.393,91$ & 42,29 & 87,00 & $28.728,29$ & 49,67 & 13,00 & $218.122,21$ & 43,13 \\
\hline Desp c/funcs. & $23.174,12$ & 5,17 & 87,00 & $3.515,18$ & 6,08 & 13,00 & $26.689,30$ & 5,28 \\
\hline Depreciação & $45.575,69$ & 10,18 & 87,00 & $6.913,16$ & 11,95 & 13,00 & $52.488,86$ & 10,38 \\
\hline Desp c/est. & $6.462,53$ & 1,44 & 87,00 & 980,27 & 1,69 & 13,00 & $7.442,80$ & 1,47 \\
\hline Juros s/ financ & $20.375,57$ & 4,55 & 87,00 & $3.090,68$ & 5,34 & 13,00 & $23.466,25$ & 4,64 \\
\hline Arrendamento & $93.806,00$ & 20,95 & 87,00 & $14.229,00$ & 24,60 & 13,00 & $108.035,00$ & 21,36 \\
\hline (=) Resultado & $138.493,11$ & 30,92 & 99,57 & 594,97 & 1,03 & 0,43 & $139.088,07$ & 27,51 \\
\hline
\end{tabular}

Nota. Fonte: Dados da pesquisa.

Legenda: AV - Análise Vertical; AH - Análise Horizontal; CPV - Custo da Produção Vendido;

MC - Margem de Contribuição.

A receita da produção foi apurada mediante a aplicação do valor cotado para venda da saca de arroz em 28/10/2014 (data da venda), cujo preço de venda unitário por saca foi de $R \$ 34,00$ (saca de $50 \mathrm{kgs}$ ) e multiplicado pela quantidade colhida em cada método de cultivo. No plantio pré-germinado, foram colhidas 13.172 sacas de arroz, enquanto no plantio direto foram colhidas 1.701 sacas. Assim, a receita do cultivo pré-germinado $(R \$ 447.848,00)$ representa $89 \%$ da receita total, enquanto a receita do plantio direto ( $\mathrm{R} \$ 57.83400)$ tem representatividade de $11 \%$ da receita total.

O cálculo do custo da produção vendida (CPV) foi apurado considerando-se os custos diretos vinculados, em que o cultivo pré-germinado apresenta $81 \%$ do total do CPV (26,79\% da receita desse plantio). Quanto ao plantio direto, o CPV representa $49,30 \%$ de sua receita. O Plantio direto apresenta Margem de Contribuição (MC) de 
A relação Custo/Volume/Lucro na Produção de Arroz: Um comparativo entre o cultivo prégerminado e o plantio direto Cristiano Sausen Soares, Lucas Wancura Barbieri

$50,70 \%$, enquanto o pré-germinado tem MC de $73,21 \%$. Aqui, identifica-se que o cultivo pré-germinado supera o plantio direto em 22,51 pontos percentuais, ou seja, apresenta maior capacidade de quitação dos gastos indiretos e fixos, além de auxiliar na formação do lucro.

Os gastos indiretos e fixos foram distribuídos aos métodos de plantio com base na área cultivada. Esses valores tiveram uma representatividade no plantio prégerminado de $42,29 \%$, sendo que o arrendamento foi aquele com maior valor $(20,95 \%$ da sua receita). O menor gasto foi com estocagem (1,44\%). No plantio direto, o gasto indireto e fixo totalizou $49,67 \%$ da sua receita. No total, esses gastos foram de $86,83 \%$ no plantio pré-germinado e $13,17 \%$ no plantio direto.

Cabe ressaltar que o arrendamento refere-se à área total e foi estabelecido em contrato, com cláusula de pagamento em sacas de arroz com uma quantidade fixada em 15,5 sacas por hectare. Com essa informação, foi identificado o total de arrendamento, distribuindo proporcionalmente a área. Para sua precificação, foi identificado o preço de venda da saca $(R \$ 34,00)$. O total de arrendamento foi de $3.177,50$ sacas, totalizando $R \$ 108.035,00$. O plantio pré-germinado, com área de 178 hectares, totalizou $R \$ 93.806,00$, enquanto o plantio direto, com área de 27 hectares, totalizou $\mathrm{R} \$ 14.229,00$.

O resultado final apresentou diferenças entre os métodos de plantio utilizados na produção da safra de arroz 2013/2014. O resultado do plantio pré-germinado alcançou $99,57 \%$ do total do resultado do período, com o valor de $R \$ 138.493,11$, enquanto no plantio direto o resultado foi de $R \$ 594,97$ (0,43\%). Ao comparar o resultado de cada plantio com a respectiva receita, observa-se que o plantio pré-germinado obteve $30,92 \%$ da receita, enquanto o plantio direto apresentou resultado de $1,03 \%$ da receita, ou seja, 29,89 pontos percentuais menores que o anterior.

Como observado, os custos e despesas fixas foram distribuídos entre os dois métodos de plantio proporcionalmente à área plantada. Dessa forma, os resultados apresentam, individualmente, os gastos relativos a cada tipo de plantio, permitindo a comparação. No entanto, não se pode afirmar que um sistema de plantio é melhor que 
A relação Custo/Volume/Lucro na Produção de Arroz: Um comparativo entre o cultivo prégerminado e o plantio direto

Cristiano Sausen Soares, Lucas Wancura Barbieri

o outro, mas, ao considerar-se o desempenho na relação custo/volume/lucro, o plantio direto apresenta resultados desfavoráveis em relação ao plantio pré-germinado. Esse resultado já era esperado pelo produtor rural que, com sua experiência, passou a utilizar o sistema de plantio pré-germinado em quase a totalidade da área cultivável.

O cultivo direto já havia apresentado custo por hectare mais elevado, em relação ao pré-germinado, demonstrando as vantagens e diferenças entre esses métodos de cultivo. A Tabela 5 apresenta as diferenças entre as variáveis custo/volume/lucro de cada método, quando apurados por unidade (hectare).

Tabela 5

Levantamento por hectare do Custo/Volume/Lucro

\begin{tabular}{|c|c|c|c|c|}
\hline Cultivo & $\begin{array}{c}\text { Pré- } \\
\text { germinado(a) }\end{array}$ & $\begin{array}{c}\text { Plantio } \\
\text { Direto(b) }\end{array}$ & $\begin{array}{c}\text { Diferença } \\
(\mathbf{a}-\mathbf{b})\end{array}$ & Resultado da análise \\
\hline Custo $(\$)$ & 673,94 & $1.055,95$ & $-382,01$ & Pré-germinado custo menor \\
\hline Volume $(\mathrm{sc})$ & 74 & 63 & 11 & Pré-germinado produtividade maior \\
\hline Lucro $(\$)$ & 778,05 & 22,04 & 756,01 & Pré-germinado lucro maior \\
\hline
\end{tabular}

Nota. Fonte: Dados da pesquisa.

Legenda: sc - Sacas

A Tabela 5 demonstra os resultados da relação entre custo, volume e lucro dos dois métodos utilizados, onde o pré-germinado apresenta vantagens em todos os itens no comparativo com o cultivo direto. A produção que utilizou o cultivo pré-germinado obteve custo menor que o plantio direto em $R \$ 382,01$. O volume de produção também foi maior em 11 sacas por hectare, e o lucro apurado no cultivo pré-germinado ( $R \$$ $778,05)$ foi $R \$ 756,01$ maior que o lucro obtido com o plantio direto ( $R \$ 22,04)$.

Cabe ressaltar que não foram ponderadas questões climáticas ou de solo, tendo em vista que a produção ocorreu em áreas equivalentes e nas mesmas condições de tempo. Contudo, para se chegar a uma situação ideal, foram calculados os pontos de equilíbrio. Salienta-se que, para o ponto de equilíbrio econômico, foi utilizado como custo de oportunidade a rentabilidade de $30 \%$ sobre a receita bruta, considerada como resultado idealizado pelo produtor rural. Os dados dessa análise estão descritos na Tabela 6. 
A relação Custo/Volume/Lucro na Produção de Arroz: Um comparativo entre o cultivo prégerminado e o plantio direto Cristiano Sausen Soares, Lucas Wancura Barbieri

Tabela 6

Levantamento dos Pontos de Equilíbrio

\begin{tabular}{|l|c|c|}
\hline \multicolumn{1}{|c|}{ Cultivo } & Pré-germinado & Direto \\
\hline Preço de Venda (R\$) & 34,00 & 34,00 \\
\hline Custo Unitário do Produto Vendido (R\$) & 9,11 & 16,76 \\
\hline Margem Contribuição Unitária (R\$) & 24,89 & 17,24 \\
\hline Ponto de Equilíbrio Contábil (Unidades/sc) & $7.609,24$ & $1.666,37$ \\
\hline Ponto de Equilíbrio Financeiro (Unidades/sc) & $5.777,52$ & $1.265,46$ \\
\hline Ponto de Equilíbrio Econômico (Unidades/sc) & $9.890,92$ & $2.166,43$ \\
\hline Ponto de Equilíbrio Contábil $(\mathrm{R} \$)$ & $258.714,06$ & $56.656,72$ \\
\hline Ponto de Equilíbrio Financeiro $(\mathrm{R} \$)$ & $196.435,68$ & $43.025,64$ \\
\hline Ponto de Equilíbrio Econômico $(\mathrm{R} \$)$ & $336.291,28$ & $73.658,62$ \\
\hline
\end{tabular}

Nota. Fonte: Dados da pesquisa.

Considerando a receita com a comercialização da produção, em que o arroz cultivado pelo método pré-germinado faturou $R \$ 447.848,00$, observa-se o ponto de equilíbrio econômico apurado de $R \$ 336.291,28$. Já a produção do plantio direto, cuja receita foi de $R \$ 57.834,00$, apresenta ponto de equilíbrio econômico de $R \$ 73.658,62$. Assim, verifica-se que o resultado esperado (lucro mínimo de $30 \%$ sobre a receita bruta) foi alcançado apenas com o cultivo pré-germinado.

\section{CONSIDERAÇÕES FINAIS}

A contabilidade de custos fornece importantes informações ao processo decisório, inclusive à atividade rural. Com esse entendimento, a pesquisa teve como objetivo analisar o resultado da produção de arroz, na safra 2013/2014, comparando dois métodos de cultivos distintos (direto e pré-germinado) em uma propriedade rural arrendada, considerando sua realidade, limitações e características na atividade da rizicultura. Para tanto, a apuração do custo por hectare foi realizada com base no método de custeio direto, sendo identificados os gastos da produção e o comportamento das variáveis custo/volume/lucro.

Quanto ao custo do arroz em relação à produção e seu resultado, foi verificado o método de cultivo que apresenta menor custo, maior produtividade e maior lucro, 
A relação Custo/Volume/Lucro na Produção de Arroz: Um comparativo entre o cultivo prégerminado e o plantio direto

Cristiano Sausen Soares, Lucas Wancura Barbieri

comparando os volumes produzidos por hectare, o custo do hectare e o lucro gerado. Conclui-se que o custo do arroz no cultivo pré-germinado foi de $\mathrm{R} \$ 673,94$ por hectare, enquanto o custo no plantio direto foi de $R \$ 1.055,95$ por hectare, alcançando uma diferença de $R \$ 382,01$. O volume produzido pelo método de cultivo pré-germinado também foi superior ao plantio direto em 11 sacas por hectare (74 sacas produzidas no plantio pré-germinado e 63 sacas produzidas no plantio direto). Assim, o lucro apurado por hectare no cultivo pré-germinado foi de $\mathrm{R} \$ 778,05$, enquanto no cultivo direto foi de $\mathrm{R} \$ 22,04$ por hectare (diferença de $\mathrm{R} \$ 756,01$ ). Com isso, o método de cultivo prégerminado obteve os melhores resultados, comparado ao método do plantio direto.

Ressalta-se que não foram consideradas no estudo variáveis climáticas ou questões relativas à capacidade produtiva do solo, tendo por base que a produção da safra 2013/2014 na propriedade analisada ocorreu em paralelo, ou seja, ao mesmo tempo, utilizando sistemas de cultivo diferentes, na mesma propriedade rural. Outro ponto a ser destacado é que o estudo não tem a pretensão de esgotar o assunto e, tampouco, definir se um método de cultivo é superior ao outro, salientando que os resultados aqui evidenciados servem para a realidade deste produtor, podendo apenas apontar uma tendência que pode ser analisada frente à decisão de escolher um método de cultivo ou outro.

Desse modo, espera-se que os achados deste estudo contribuam aos empresários rurais e produtores agrícolas no processo decisório, subsidiando a análise de resultados da produção rural, além de auxiliar os profissionais de contabilidade quanto aos elementos de estruturação da apuração de custos agrícolas.

Para futuros estudos, sugere-se a elaboração de uma pesquisa coletando dados históricos de períodos anteriores ou mais relativos a mais de uma safra, para testar o comportamento aqui identificado. Outra sugestão é buscar localidades diferentes para realizar um estudo comparativo entre propriedades distintas, com a finalidade de verificar se as alterações estruturais apresentaram resultados compatíveis. 
A relação Custo/Volume/Lucro na Produção de Arroz: Um comparativo entre o cultivo prégerminado e o plantio direto Cristiano Sausen Soares, Lucas Wancura Barbieri

\section{REFERÊNCIAS}

Backes, R. G., Kuhn, C. M. S., Perleberg, C. R., Dalben, L. C., Wiest, L., \& Alberti, J. A. (2007). Aplicação do método de custeio RKW em uma cooperativa agrícola. Revista Custos e @gronegócio, (3a ed. especial).

Bassani, T. P., \& Breda, L. (2012). Análise dos custos de produção, da produtividade e da rentabilidade em relação a três tecnologias de cultivo de arroz irrigado na fazenda São Sebastião, Querência do Norte/PR. Revista Custos e @gronegócio, 8 (2).

Bomfim, E. de A., \& Passareli, J. (2006). Custos e formação de preços. (4a ed.). São Paulo: IOB Thomson.

Borges, A. P. M., Mainardi, A., \& Velasquez, M. D. P. (2013). Avaliação do Custo de Produção de Arroz em Pequenas Propriedades Rurais do Rio Grande do Sul: Um Estudo de Caso. Revista em Agronegócio e Meio Ambiente, 6(1), 99.

Bornia, A. C. (2002). Análise gerencial de custos: aplicação em empresas modernas. Porto Alegre: Bookman.

Borilli, S. P., Philippsen, R. B., Ribeiro, R. G., \& Hofer, E. (2008). O uso da contabilidade rural como uma ferramenta gerencial: um estudo de caso dos produtores rurais no município de Toledo-PR. Revista de Ciências Empresariais da UNIPAR, 6(1).

Brondani, G. Vey, I. H., Madruga, S. R., Trindade, L. L., \& Venturini, J. C. (2006). Diferenciais de custos em culturas de arroz: a experiência do Rio Grande do Sul. Revista Universo Contábil, 2(1), 61-74.

Callado, A. L. C., Albuquerque, J. de L., \& Silva, M. N. (2007). Análise da Relação Custo/Volume/Lucro na Agricultura Familiar: O caso do Consórcio Mamona/Feijão. Custos e @gronegócio on line, 3 (1), 38-60.

Carastan, J. T. (1999, julho). Custo meta e custo padrão como instrumentos do planejamento empresarial para obter vantagem competitiva. Anais do Congresso Brasileiro de Custos, São Paulo, SP Brasil, 6.

CONAB - Companhia Nacional de Abastecimento (2015). A cultura do Arroz. Org. Aroldo Antonio de Oliveira Neto. Brasília, CONAB.

EMBRAPA. Empresa Brasileira para a Pesquisa Agropecuária (2005). Cultivo do arroz irrigado no Brasil. Recuperado de: <http://www.embrapa.gov.br>. 
Ferreira, J. D., Martins, H. H., Orlandi, T. \& Rocha Jr., W. F. da (2015). Fomento à pecuária de leite da Primato cooperativa agroindustrial. Revista Capital CientíficoEletrônica (RCCe), 13(1), 135-149.

Hillmann, M. (2001). Ponto de equilíbrio aplicado a sistemas de produção de arroz irrigado. ConTexto, 1(1).

Hofer, E., Rauber, A. J., Diesel, A., \& Wagner, M. (2006). Gestão de custos aplicada ao agronegócio: culturas temporárias. Contabilidade Vista \& Revista, 17(1).

Leone, G. S. G. (2000). Custos: Planejamento, Implantação e Controle. São Paulo: Atlas.

Martins, E. (2006). Contabilidade de custos. São Paulo: Atlas.

Megliorini, E. (2012). Custos: análise e gestão. São Paulo: Pearson Prentice Hall.

Perez Jr., J. H. Oliveira, L. M. de., \& Costa, R. G. (2012). Gestão Estratégica de Custos: textos, casos práticos e testes com respostas. São Paulo: Atlas.

Richardson, R. J. (1999). Pesquisa social: métodos e técnicas. São Paulo: Atlas.

Santos, N. S. dos (2007). Uma avaliação do custo de oportunidade de estocagem de produtos agroindustriais: o caso do arroz.Revista Custos e @gronegócio online, 3 (2).

Santos, G. J., Marion, J. C. \& Segatti, S. (2008). Administração de custos na agropecuária. São Paulo: Atlas.

Souza, R. S., Arbage, A. P., \& Corazza, C. (2006). Gerenciamento da cadeia de suprimentos de engenhos de arroz no Rio Grande do Sul: um estudo à luz da economia dos custos de transação. Organizações Rurais \& Agroindustriais, 8(1), 49-57.

Valle, F. (1987). Manual de contabilidade agrária. São Paulo: Atlas.

Velasquez, M. D. P., Santos, P. C., \& Borges, A. P. M. (2012, novembro). Custo total do beneficiamento do arroz em uma cooperativa agrícola. Anais do Congresso Brasileiro de Custos. Bento Gonçalves, RS. Brasil, 19.

Venturini, J. C., Brondani, G., Madruga, S. R., Costa, P. R. D. J., \& Trindade, L. L. (2006, novembro). Orizicultura mutagênica: Diferenciação de Custos do plantio 
A relação Custo/Volume/Lucro na Produção de Arroz: Um comparativo entre o cultivo prégerminado e o plantio direto Cristiano Sausen Soares, Lucas Wancura Barbieri

convencional e direto. Anais do Congresso Brasileiro de Custos. Belo Horizonte, MG, Brasil, 13.

Vilpoux, O. (2011). Desempenho dos arranjos institucionais e minimização dos custos de transação: transações entre produtores e fecularias de mandioca. Revista de Economia e Sociologia Rural, 49(2), 271-294.

Wander, A. E. (2006). A competitividade do agronegócio brasileiro de arroz. Custos e @gronegócio on line, 2(1), 2-15.

Warren, C. S., Reeve, J. M., \& Fess, E. (2001). Contabilidade gerencial. Tradução: André O. D. Castro. São Paulo: Pioneira thomson learning.

Yin, R. K. (2001). Estudo de Caso: Planejamento e métodos. Porto Alegre: Bookman.

Wernke, R. (2001). Gestão de Custos. São Paulo: Atlas.

Williamson, O. E. (1985). The economic intstitutions of capitalism. Simon and Schuster.

Data de Submissão: 18/07/2017

Data de Aceite: 10/11/2017 